\title{
Green Bio-based Aerogels Prepared from Recycled Cellulose Fiber Suspensions
}

\author{
Liang Wang and Miguel Sánchez-Soto*
}

Recycled cellulose fibers ( $\mathrm{RCF}$ ) from waste paper were utilized to prepare bio-based aerogels through an environmentally friendly freeze-drying method. Food thickening agent sodium carboxymethyl cellulose (CMC) served as matrix in the bio-aerogels. The microstructures and mechanical properties of the aerogels have been studied as a function of RCF/CMC content. Sodium montmorrilonite $\left(\mathrm{Na}^{+}-\mathrm{MMT}\right)$ and ammonium polyphosphate (APP) were added to enhance the thermal stability and flame retardancy, which were investigated by thermogravimetric analysis (TGA) and cone calorimeter respectively. It was found that the $\mathrm{Na}^{+}$-MMT significantly improved the fire retardancy of the aerogels and APP played a synergistic effect with it. The initial decomposition temperature increased by $15^{\circ} \mathrm{C}$ and the peak of heat release rate decreased from 90 to $49.5 \mathrm{kw} / \mathrm{m}^{2}$ in the presence of $33 \%$ clay. Addition of APP further increased the residue amount and reduced the fire growth rate. Fourier transform infrared spectroscopy (FTIR) was used to analyse the char formed after cone calorimeter tests.

\section{Introduction}

Due to their low price and excellent properties, petrol-based foams are widely used in packing and insulating applications. However, large-scale usage of traditional polymeric foams has brought significant environmental problems due to their nonbiodegradable character.

Aerogels are lightweight materials that can be obtained from renewable resources. They have been subject of considerable recently interest as promising bio-based alternatives for petroleum-derived foams. The potential applications of these bioaerogels include lightweight construction, separation agents ${ }^{1,2}$, sensors ${ }^{3}$ or supercapacitors ${ }^{4}$, to mention a few.

However, one of the most important issues that need to be addressed prior to the general use of bio-based aerogels is the improvement of their mechanical performance. Different approaches have been taken to enhance the mechanical properties of these aerogels, such as the addition of clay ${ }^{5}$, the creation of chemical crosslinks ${ }^{6}$ or the reinforcement with natural fibers ${ }^{7}$. Recently, strong and flexible aerogels based on cellulose nanofibers (CNFs) from wood pulp were prepared via freezedrying ${ }^{8,9}$. Robust CNFs aerogels were created due to the presence of strong hydrogen bonding between the fibers. Also, it was possible to alter the microstructures and mechanical properties by changing either the freeze-drying condition or the CNFs concentration in the precursor solution ${ }^{10}$.

Apart of natural sources like wood or plants, cellulose fibers can be obtained from paper or cardboard wastes. Although their mechanical properties are interior to than the ones of CNFs, this type of fibers could be used to make successful green industrial products. According to the statistics, recycling one ton of paper saves roughly 17 trees, 3.3 cubic yards of landfill space, 360 gallons of water, 100 gallons of gasoline, 60 pounds of air pollutants, 10401 kilowatts of electricity ${ }^{11}$. Therefore, aerogels based on recycled cellulose fibers (RCF) could be a new application for these residues. To the best of our knowledge, the preparation of aerogels based on recycled cellulose has not been yet reported.

The earlier works from CNFs-starch biofoams ${ }^{12,13}$ suggests that it may be possible to obtain high-performance bio-based aerogels by combining cellulose fibers with polymers based on polysaccharides. Sodium carboxymethylcellulose (CMC) is an anionic water-soluble polysaccharide derivative with carboxymethyl groups bound to hydroxyl groups of the glucopyranose monomers that make up the cellulose backbone. Building on the earlier experience of preparing cellulose nanocomposite films ${ }^{14}$, CMC addition is also considered a possible way to improve the mechanical properties of $\mathrm{RCF}$ aerogels.

Flame resistance is another important parameter for foams. Previous work showed that sodium montmorillonite clay $\left(\mathrm{Na}^{+}-\right.$ MMT) is an efficient filler to enhance flame retardancy and thermal stability of the aerogels ${ }^{15,16}$. The presence of clay leads to the formation of a barrier during burning which isolates the underlying materials from the heat radiation. Ammonium polyphosphate (APP), a halogen-free intumescent flame retardant agent, has been studied in polyvinyl alcohol (PVOH)/clay aerogel composites, showing positive effects on the fire retardancy by a chemical reaction in the condensed phase ${ }^{17}$. On the other hand, Zhao's work ${ }^{18}$ showed that layered double hydroxide (LDH) played a synergistic role with APP on fire retardancy of PVOH. Clay has a similar structure than $\mathrm{LDH}$, therefore a synergistic 
effect between clay and APP may be expected.

In the present study, a fully biodegradable biocomposite based on RCF/CMC was produced through a freeze-drying process. In addition, clay and APP were used to improve the flame retardancy of the prepared bio-based aerogels and to preserve their environmentally friendly character. The microstructures as well as the mechanical, thermal and fire behaviour of the bio-aerogels were characterized.

\section{Experimental}

\subsection{Materials}

The raw material for preparing the RCF came from two different sources. Waste paper (75 wt $\%$ ) was obtained from the output of paper mill purifying plants. Cardboard (25 wt $\%$ ) was obtained from end-use cardboard boxes. After mechanical shredding, the mixture was hydrated by adding water at $50{ }^{\circ} \mathrm{C}$. RCF were disintegrated from the paper/cardboard waste through a bioprocess involving enzymatic treatment of pulp using hydrolases and oxidoreductases that were left to react for 1 hour at the same temperature ${ }^{19}$. A pulp containing $10 \mathrm{wt} \%$ solids was finally obtained and stored in the refrigerator $\left(4{ }^{\circ} \mathrm{C}\right)$ for further use. As mentioned, this pulp was formed by $75 \%$ of short cellulose fibers $(0.81 \pm 0.33 \mathrm{~mm})$ and $25 \%$ of long cellulose fibers $(1.62 \pm 0.47 \mathrm{~mm})$ according to the different residue source.

Carboxymethylcellulose, Walocel CRT 1000 PA 07, was kindly supplied by Dowwolff Cellulosic. Montmorillonite $\left(\mathrm{Na}^{+}-\right.$ MMT), PGW grade, density $2.6 \mathrm{~g} / \mathrm{cm}^{3}$, was purchased from Nanocor Inc. Ammonium Polyphosphate (APP) compound, Budit3079, was received from Budenheim Ibérica. All ingredients were used without further purification.

\subsection{Aerogel preparation}

$10 \mathrm{wt} \%$ of RCF pulp was initially diluted to appropriate concentration, followed by addition of the desired amount of CMC powder. The resultant suspensions were mixed under mechanical stirring at $80{ }^{\circ} \mathrm{C}$ until achieving homogenous mixtures (precursor suspensions). Then they were transferred into cylindrical vials of $30 \mathrm{~mm}$ diameter or into square-shaped molds $(100 \times 100 \mathrm{~mm})$ and frozen over night in a freezer operating at -27 ${ }^{\circ} \mathrm{C}$. Samples were finally dried in a lyophilizer (Telstar Lyoquest) for 4 days under a condenser temperature of $-80{ }^{\circ} \mathrm{C}$ and vacuum of $0.01 \mathrm{mbar}$. The denomination of obtained samples is according to the constituents used followed by its respective concentration percentage in $100 \mathrm{ml}$ of aqueous solution. For instance, F5C2.5 contains $5 \mathrm{wt} \% \mathrm{RCF}$ and $2.5 \mathrm{wt} \% \mathrm{CMC}$; where $\mathrm{F}$ and $\mathrm{C}$ stand for $\mathrm{RCF}$ and CMC respectively. Same solid amounts remained in the aerogels when the ice is removed.

Flame-retardant modified aerogels were prepared in a similar way. Firstly, clay and APP powders were both dispersed in (50 $\mathrm{ml}$ of) deionized (DI) water using an IKA Ultra-turrax disperser operated at $8000 \mathrm{rpm}$ for $30 \mathrm{~min}$. Then $50 \mathrm{ml}$ of $\mathrm{CMC} / \mathrm{RCF}$ suspension which contained $2.5 \mathrm{~g}$ of RCF and $2.5 \mathrm{~g}$ of $\mathrm{CMC}$ was added. The mixture was mechanically stirred until they became homogeneous and then it was freeze-dried. The resultant aerogels were named as MxAy, where $\mathrm{M}$ and A represent MMT and APP respectively; $x$ and $y$ are their concentration percentage in the final precursor suspension. For example, M2.5A0.5 aerogel was prepared adding $50 \mathrm{ml}$ water containing $2.5 \mathrm{~g}$ of MMT and
$0.5 \mathrm{~g}$ of APP to $50 \mathrm{ml}$ water containing $2.5 \mathrm{~g}$ RCF and $2.5 \mathrm{~g}$ of CMC. The composition summary of all the prepared samples is shown in Table 1.

60 Table 1. Composition of the precursor suspension for preparing the aerogels.

\begin{tabular}{ccccc}
\hline Samples & RCF (wt $\%)$ & CMC (wt $\%)$ & Clay (wt $\%)$ & APP (wt $)$ \\
\hline F2.5C0 & 2.5 & & & \\
F0C2.5 & & 2.5 & & \\
F2.5C1.2 & 2.5 & 1.25 & & \\
F2.5C2.5 & 2.5 & 2.5 & & \\
F3.7C2.5 & 3.75 & 2.5 & & \\
F5C2.5 & 5 & 2.5 & & \\
M2.5A0 & 2.5 & 2.5 & 2.5 & \\
M2.5A0.2 & 2.5 & 2.5 & 2.5 & 0.25 \\
M2.5A0.5 & 2.5 & 2.5 & 2.5 & 0.5 \\
M0A0.5 & 2.5 & 2.5 & & 0.5 \\
\hline
\end{tabular}

\subsection{Characterization}

The microstructures of the aerogels were observed using a Scanning Electron Microscope (SEM, Jeol 5610, Japan) operated at $10 \mathrm{kV}$. Prior to analysis, aerogels were cryofractured, then dried in vacuum and finally coated with a $\mathrm{Pd} / \mathrm{Au}$ layer.

The apparent densities ( $\rho_{\text {app }}$ ) were calculated from the sample weight divided by the sample volume. Weights were recorded using a precision balance and dimensions were measured by a digital outside caliper on cylinder aerogels having polished flat surfaces. Five replicas of each sample were taken.

Compression tests were conducted on a Galdabini (Italy) universal testing machine using a load cell of $1 \mathrm{kN}$ following ISO 604 standard. The crosshead rate and maximum strain were kept constant at $1 \mathrm{~mm} / \mathrm{min}$ and $70 \%$, respectively. Compressive moduli were extracted from the slopes of the linear portions of the stress-strain curves. The yield stress was taken as the stress at the intersection between the tangent line of the elastic region and the tangent line of the stress plateau segment. The energy absorbed was calculated as the integrated area of the stress-strain curve.

The thermal stability of the aerogels was investigated on a Mettler Toledo TGA/DSC1 instrument. Proper amount of samples (less than $10 \mathrm{mg}$ ) were placed in alumina pans and heated at a rate of $10{ }^{\circ} \mathrm{C} \mathrm{min}^{-1}$ from 30 to $600{ }^{\circ} \mathrm{C}$ under dry air atmosphere.

The burning behaviour of modified aerogels was measured on a cone calorimeter (Ineltec BECC model, Spain) following 90 ISO 5660 procedure. Square specimens with dimensions of $100 \times 100 \times 7 \mathrm{~mm}$ were tested with an external heat flux of 50 $\mathrm{kWm}^{-2}$.

Fourier transform infrared (FTIR) analyses were conducted using a Nicolet 6700 spectrophotometer in the attenuated total reflectance (ATR) mode. The spectrum was based on 30 scans with $1 \mathrm{~cm}^{-1}$ resolution across a wavenumber interval between 4000 and $400 \mathrm{~cm}^{-1}$.

\section{Results and Discussion}




\subsection{SEM analysis.}

The microstructure of pure RCF aerogel is shown in Figure 1a. In the micrograph, it can be seen that the fibers are distributed randomly without a defined alignment. Due to their large dimensions, fibers are not pushed aside by the growing ice and therefore no predominant orientation is observed. In contrast, $\mathrm{CNF}$ aerogels as previously reported in literature ${ }^{8}$ displayed a cellular cross-section in which the cell wall consisted of CNFs, as a result of the much smaller fiber dimensions and faster applied

\section{freezing rate}

Interestingly, when $1.25 \mathrm{wt} \% \mathrm{CMC}$ was introduced into the precursor solution, a lamellar structure appeared in the resultant sample F2.5C1.2, as seen in Figure 1b. The molecules of CMC are pushed into interstitial regions of the ice upon the ice crystals growth. After ice sublimation, laminas are remained forming the typical "house of cards" aerogel structure ${ }^{20}$. Some fibers can also be found bridging the channels left by the ice.
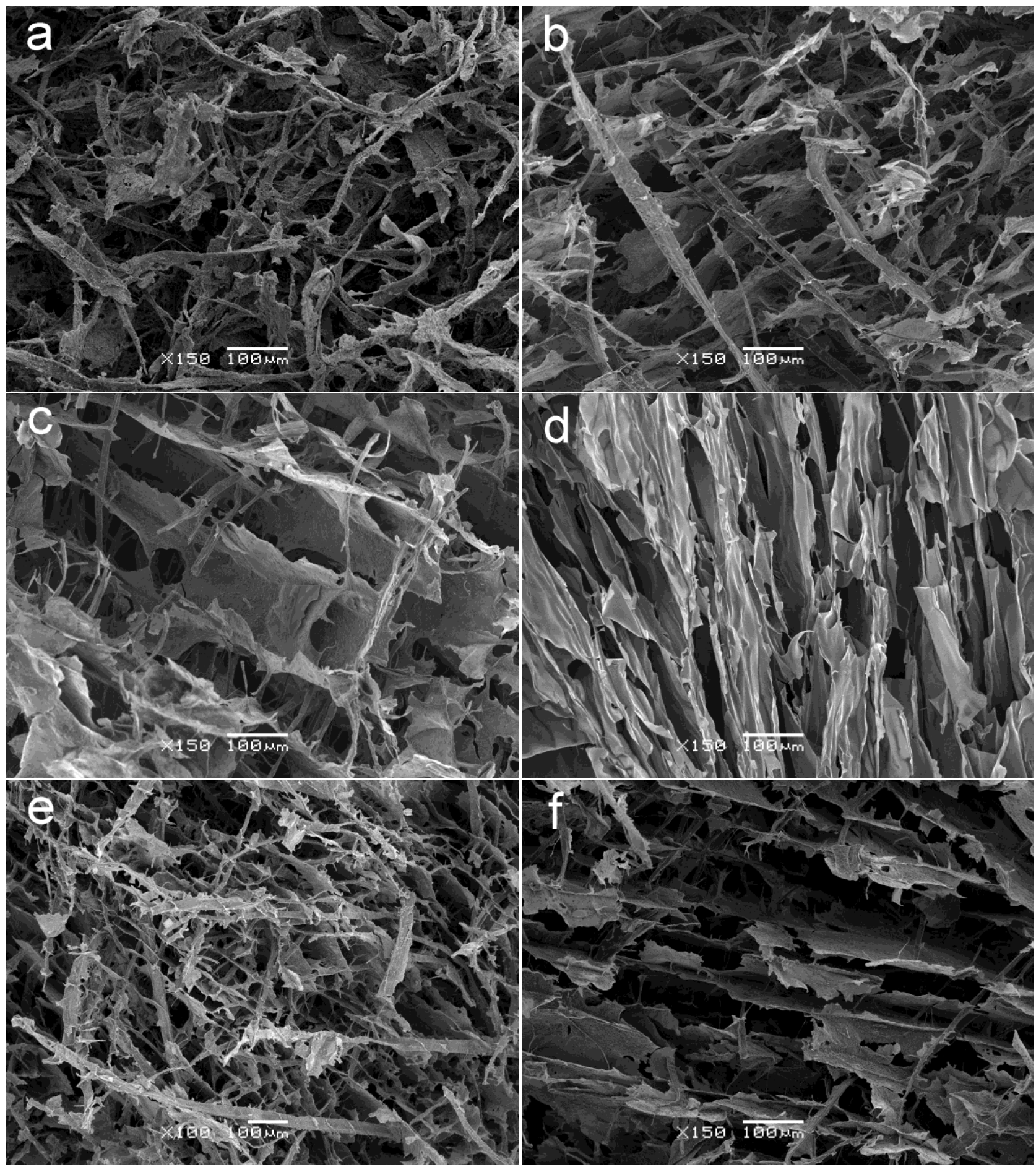

Figure 1. SEM micrographs of RCF/CMC aerogels: (a) F2.5C0, (b) F2.5C1.2, (c) F2.5C2.5, (d) F0C2.5, (e) F5C2.5, (f) M2.5A0. 
As measured by the apparent density, the porosity of aerogels decreased with the increase of CMC content, being more evident when Figure 1b and Figure 1c are compared. This effect is related to the amount of solids in the precursor suspension. The higher the amount of solids in the suspension, the lower is the ice expansion, thus decreasing the final apparent density. Moreover, aerogels with increasing amount of solids exhibited thicker layers, which was associated with the slow ice crystals growth in viscous suspensions.

As expected, pure CMC aerogels displayed smooth layer surface (Figure 1d), which was similar with previous work on aerogels prepared from different types of thickening agents 515 . By adding $5 \mathrm{wt} \%$ of RCF (F5C2.5), the lamellar structure was lost due to fiber aggregation (Figure 1e). The maximum content of fiber to avoid this phenomenon was found to be $3.75 \mathrm{wt} \%$.

For the case of flame retardancy modified aerogels (Figure 1f), the presence of isolated clay layers suggested that aerogel laminas were formed via CMC encapsulating clay nanoparticles again with intercalated fibers. Further addition of APP did not affect the microstructures of the RCF/CMC/clay aerogels.

\subsection{Compression properties.}

The compressive stress-strain curves of the samples are presented in Figure 2. For most samples, the stress-strain behavior was linear at low strains and the slopes strongly depending on densities. At this stage, the deformation was mainly due to elastic bending of the cell walls. Then a "plateau zone" appeared due to cell collapse. Typical elastic-plastic polymer foams showed a horizontal plateau region after reaching a yield stress ${ }^{21}$. However, the present aerogel composites, especially those with comparatively higher densities, displayed a gradually increasing stress in this stage. At high strains, the densification occurred with the steep rising of the stress which is due to the opposing cell walls touching ${ }^{21}$. The parameters defining the compressive mechanical behaviour of the aerogels are summarized in Table 2 .

The sample F2.5C0 showed much lower mechanical properties compared to those found in literature for CNFs aerogels which had a modulus of $1.36 \mathrm{MPa}$ and yield strength of $92.7 \mathrm{KPa}$ with a similar density $\left(0.035 \mathrm{~g} / \mathrm{cm}^{3}\right)^{8}$. This is because $\mathrm{CNF}$ aerogels have a cellular structure as well as the cell walls consist of nanofibers with much higher specific surface and mechanical properties than the ones used in this work.

Pure CMC aerogel, F0C2.5, had a similar density than $\mathrm{F} 2.5 \mathrm{C} 0$ but behaved in a more rigid way. Also, the mechanical properties of $\mathrm{F} 2.5 \mathrm{C} 0$ were enhanced through adding $1.25 \mathrm{wt} \%$ of $\mathrm{CMC}$ into its precursor suspension. Both the specific modulus and absorbed energy were increased by nearly 4 times. The specific yield stress became 5.7 times higher. Two factors contribute to this effect. Firstly, CMC can form stable structures due to the inherent self-association of the molecules via hydrogen bonding ${ }^{22}$. In second term, CMC and fibers have similar chemical structures and polarities which lead to the development of a good adhesion between them.

A monotonic increase in the specific modulus and yield strength with the increase of CMC concentration is observed in Table 2. When more CMC is added to the aerogels, the density of links between fibers becomes higher, improving the integrity of the materials. The composite F2.5C2.5 had a modulus of 2.87 $\mathrm{MPa}$ which was much higher than the modulus of cellulose whisker aerogel $(778 \mathrm{kPa})$ with a density of $0.11 \mathrm{~g} / \mathrm{cm}^{3}{ }^{23}$. F2.5C2.5 presented a layered architecture connected with fibers (Figure 1c) as well as the strong molecular affinity between CMC and RCF as previously discussed. This makes the resultant aerogels behave in a much more rigid manner.
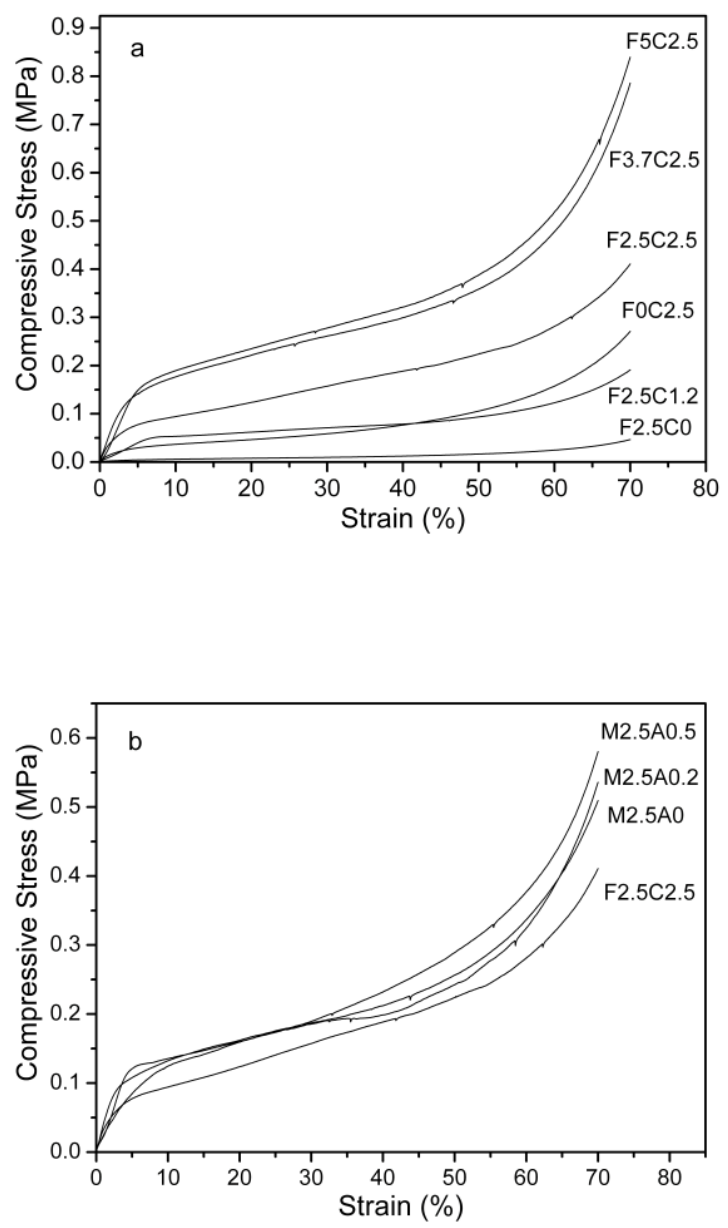

Figure 2. Compressive stress-strain curves of RCF/ CMC aerogels (a) and flame retardancy modified aerogels (b). 
Table 2. Mechanical properties of aerogels based on RCF/CMC.

\begin{tabular}{ccccccc} 
Samples & $\begin{array}{c}\text { Apparent density } \\
(\mathrm{g} / \mathrm{cm} 3)\end{array}$ & $\begin{array}{c}\text { Compressive Modulus } \\
(\mathrm{MPa})\end{array}$ & $\begin{array}{c}\text { Specific Modulus } \\
\left(\mathrm{MPa} / \mathrm{g} \mathrm{cm}^{-3}\right)\end{array}$ & $\begin{array}{c}\text { Yield Strength } \\
(\mathrm{kPa})\end{array}$ & $\begin{array}{c}\text { Specific Yield Strength } \\
(\mathrm{kPa} / \mathrm{g} \mathrm{cm})\end{array}$ & $\begin{array}{c}\text { Energy absorbed at } \\
70 \% \mathrm{strain}\left(\mathrm{kJ} / \mathrm{m}^{3}\right)\end{array}$ \\
\hline F2.5C0 & 0.03 & $0.13 \pm 0.01$ & $4.23 \pm 0.33$ & $5.7 \pm 0.4$ & $191 \pm 16$ & $10.9 \pm 1.9$ \\
F0C2.5 & 0.036 & $1.56 \pm 0.17$ & $43.05 \pm 5.07$ & $24.7 \pm 1.5$ & $679 \pm 41$ & $60 \pm 1.3$ \\
F2.5C1.2 & 0.042 & $1.15 \pm 0.34$ & $23.39 \pm 2.26$ & $46.1 \pm 5.2$ & $1093 \pm 123$ & $55.9 \pm 2.3$ \\
F2.5C2.5 & 0.057 & $2.87 \pm 0.78$ & $56.21 \pm 8.91$ & $77.6 \pm 4.2$ & $1341 \pm 76$ & $132.2 \pm 3.9$ \\
F3.7C2.5 & 0.075 & $5.04 \pm 0.49$ & $66.59 \pm 7.01$ & $133.7 \pm 7.4$ & $1767 \pm 92$ & $201.6 \pm 14.9$ \\
F5C2.5 & 0.087 & $4.16 \pm 1.21$ & $61.31 \pm 5.62$ & $164 \pm 15.8$ & $1880 \pm 180$ & $245.8 \pm 12.9$ \\
M2.5A0 & 0.076 & $3.63 \pm 0.52$ & $48.73 \pm 6.54$ & $89.1 \pm 1.8$ & $1436 \pm 478$ & $154.8 \pm 4.4$ \\
M2.5A0.2 & 0.082 & $3.25 \pm 0.49$ & $39.31 \pm 5.83$ & $109 \pm 43.8$ & $1325 \pm 518$ & $174.2 \pm 10.7$ \\
M2.5A0.5 & 0.083 & $2.34 \pm 0.71$ & $28.25 \pm 7.75$ & $63.6 \pm 26.1$ & $759 \pm 298$ & $155.8 \pm 6.6$
\end{tabular}

In order to investigate further the effect of fiber content on the mechanical properties of RCF/CMC aerogel composites, aerogels with constant CMC concentration (2.5 wt\%) were prepared. Table 2 shows that the modulus of the aerogels increased with the RCF content up to $3.75 \mathrm{wt} \%$ where a maximum was reached. F3.7C2.5 presented mechanical properties comparable to the ones of the CNF aerogel ${ }^{8}$. However, when the RCF amount was further increased, there was no significant change in mechanical properties. This could be due to fiber aggregation in the precursor solution when its concentration reached a critical value. When fibers were in excess, they remained isolated in the obtained aerogel, having a lack of adhesion with CMC (Figure 1e).

In the case of flame retardant modified aerogels, there was no significant improvement in the mechanical properties by the clay presence. Both CMC and clay possess negative charges on their surface and a weak interaction between them may be expected. This phenomenon was likewise found when testing clay-CMC films ${ }^{14}$. However, in the present case, clay was added to improve thermal and fire properties rather than the mechanical ones. APP incorporation reduced the mechanical properties of the $\mathrm{RCF} / \mathrm{CMC} /$ clay aerogels in a similar way as described in previous studies on PVA-clay-APP systems, which showed that 2 the addition of APP had a side effect on the mechanical properties ${ }^{17}$. The slight hydrolysis of APP decreased the $\mathrm{pH}$ value of the suspension, which had a negative impact on the interaction between fibers and CMC.

\subsection{Thermal Stability.}

Generally, the TGA patterns of RCF/CMC aerogels can be divided into three steps (Figure 3). The first step below $150{ }^{\circ} \mathrm{C}$ is due to the evaporation of moisture absorbed by the aerogels. In the second stage, a rapid mass loss occurred above $250{ }^{\circ} \mathrm{C}$. It involves oxidative decomposition of the cellulosic molecular chains. A further increase in temperature leads to a slow thermal degradation, followed by a carbonization process in the final stage ${ }^{24}$. With the addition of APP or clay, the corresponding TGA curves changed, showing a new degradation step around $400{ }^{\circ} \mathrm{C}$. This step may be due to the formation of char which delays the decomposition rate. The parameters for the thermal stability of each sample, such as the onset of decomposition temperature $\mathrm{T}_{\mathrm{d} 5 \%}$, the temperature at maximum weight loss rate $\mathrm{T}_{\mathrm{dmax}}$, the maximum weight loss rate $\mathrm{dW} / \mathrm{dT}_{\max }$, and the residue amount at $600{ }^{\circ} \mathrm{C} \mathrm{W}_{\mathrm{R}}$ are listed in Table $3 . \mathrm{T}_{\mathrm{d} 5 \%}$ is defined as the temperature at which $5 \%$ weight loss beyond total water evaporation, which is thought to occur at $150{ }^{\circ} \mathrm{C}^{5}$.

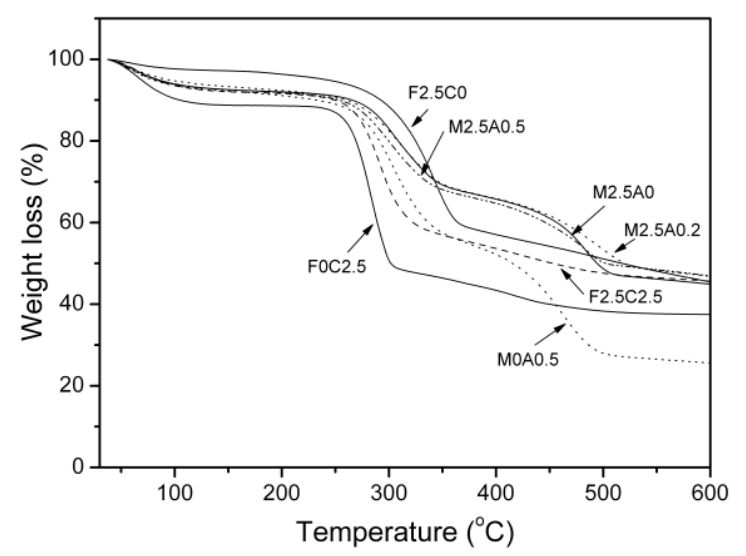

Figure 3. TGA weight loss curves of aerogels based on RCF/CMC

Sample F2.5C2.5 showed a decomposition behaviour which was intermediate between the pure components. RCF showed a lower rate of degradation and a higher stability than CMC due to its higher crystallinity degree ${ }^{25}$.

With the addition of clay, the thermal stability of the aerogel was enhanced. Both $\mathrm{T}_{\mathrm{d} 5 \%}$ and $\mathrm{T}_{\mathrm{dmax}}$ increased by nearly $15^{\circ} \mathrm{C}$, 
and the maximum weight loss rate dropped by about $50 \%$. Inorganic clay nanoparticles played a role of thermal insulator, protecting the polymer of being decomposed rapidly as has been reported in previous works ${ }^{15}$. The incorporation of $0.5 \mathrm{wt} \%$ of APP into F2.5C2.5 did not markedly affect the $\mathrm{T}_{\mathrm{d} 5 \%}$. However, the $\mathrm{T}_{\mathrm{dmax}}$ increased by nearly $15^{\circ} \mathrm{C}$ and $\mathrm{dW} / \mathrm{dT}_{\max }$ decreased from 0.72 to 0.53 . This suggests that the kinetic thermal stability was enhanced due to the retardant effect of the APP. APP is able to react with the hydroxyl groups of the cellulose pyranose ring to yield a cellular compact char, limiting the heat transfer ${ }^{18}$.

M2.5A0.2 showed slightly higher char residue and lower decomposition rate as compared to $\mathrm{M} 2.5 \mathrm{~A} 0$. Increasing the amount of APP to $0.5 \mathrm{wt} \%, \mathrm{~T}_{\mathrm{dmax}}$ increased by $7{ }^{\circ} \mathrm{C}$, indicating a certain synergistic effect on the thermal stability. However, the addition of APP lowered $\mathrm{T}_{\mathrm{d} 5 \%}$ of $\mathrm{M} 2.5 \mathrm{~A} 0$ because the APP decomposition started at a lower temperature (about $200{ }^{\circ} \mathrm{C}$ ).

Table 3. TGA data of aerogels based on RCF/CMC

\begin{tabular}{ccccc}
\hline Samples & $\mathrm{T}_{\mathrm{d} 5 \%}\left({ }^{\circ} \mathrm{C}\right)$ & $\mathrm{T}_{\mathrm{d} \max }\left({ }^{\circ} \mathrm{C}\right)$ & $\mathrm{dW} / \mathrm{dT}_{\max }\left(\% /{ }^{\circ} \mathrm{C}\right)$ & $\mathrm{W}_{\mathrm{R}}(\%)$ \\
\hline $\mathrm{F} 0 \mathrm{C} 2.5$ & 260.7 & 282.6 & 1.12 & 37.5 \\
$\mathrm{~F} 2.5 \mathrm{C} 0$ & 276.6 & 342.2 & 0.6 & 45.2 \\
$\mathrm{~F} 2.5 \mathrm{C} 2.5$ & 265.8 & 290.7 & 0.72 & 45.6 \\
M2.5A0 & 281.6 & 304.3 & 0.35 & 44.9 \\
$\mathrm{M} 2.5 \mathrm{~A} 0.2$ & 270.9 & 301.1 & 0.33 & 46.8 \\
M2.5A0.5 & 272.2 & 311.3 & 0.31 & 46.9 \\
M0A0.5 & 262.8 & 304.3 & 0.53 & 25.5 \\
\hline
\end{tabular}

Table 4.Combustive parameters of flame retardancy modified aerogels

\begin{tabular}{cccccccc}
\hline Samples & $\begin{array}{c}\text { Mass } \\
(\mathrm{g})\end{array}$ & $\mathrm{t}_{\mathrm{e}}(\mathrm{s})$ & $\begin{array}{c}\text { TTPHRR } \\
(\mathrm{s})\end{array}$ & $\begin{array}{c}\text { PHRR } \\
\left(\mathrm{kW} / \mathrm{m}^{2}\right)\end{array}$ & $\begin{array}{c}\text { FGR } \\
\left(\mathrm{kW} / \mathrm{m}^{2} \mathrm{~s}\right)\end{array}$ & $\begin{array}{c}\text { THR } \\
\left(\mathrm{MJ} / \mathrm{m}^{2}\right)\end{array}$ & $\begin{array}{c}\text { Residue } \\
(\%)\end{array}$ \\
\hline F2.5C2.5 & 4 & 106 & 30 & 90.2 & 3 & 5.03 & 23.1 \\
$\mathrm{M} 2.5 \mathrm{~A} 0$ & 5.1 & 28 & 48 & 49.5 & 1.03 & 4.64 & 41.2 \\
$\mathrm{M} 2.5 \mathrm{~A} 0.2$ & 5.4 & 36 & 51 & 28.7 & 0.56 & 4.05 & 43.6 \\
$\mathrm{M} 2.5 \mathrm{~A} 0.5$ & 5.5 & 15 & 48 & 39.8 & 0.83 & 3.5 & 42.9 \\
M0A0.5 & 4.8 & 45 & 39 & 81.6 & 2.1 & 5.58 & 24 \\
\hline
\end{tabular}

\subsection{Combustion behaviour.}

Cone calorimetry is a testing method which can quantitatively analyze flammability by measuring the heat release rate (HRR) from a sample on bench-scale, and is widely used to predict the burning behaviour of materials under real fire conditions. The fire behaviour of modified RCF/CMC aerogels was investigated using this method. The relevant flammability data of samples, such as the peak of heat release rate (PHRR), total heat release (THR), time to peak of heat release rate (TTPHRR), fire growth rate (FGA), time to flame extinguish $\left(\mathrm{t}_{\mathrm{e}}\right)$ and residue amount, are listed in Table 4. The combustion patterns in terms of heat release rate as a function of their burning time are illustrated in Figure 4. In addition, photos of the char of flame retardant-modified aerogels after cone calorimetry tests are shown in Figure 5.

Unmodified sample displayed a typical combustion behaviour described in previous works on bio-based aerogels ${ }^{26}$. Its HRR pattern started with a vigorous burning episode followed by a long fire disappearing region with low HRR values. With the addition of APP or clay, the initial combustion step was delayed and HRR plots decreased in height and flattened out prior to completing the test. Sample M0A0.5 should show a continuous HRR plot, however it displayed a combustive pattern with a valley in the initial stage. This is because the sample is cracked upon burning (see Figure 5b), breaking the protective layer, which transiently allows the fire transmission from the top to the bottom of sample.

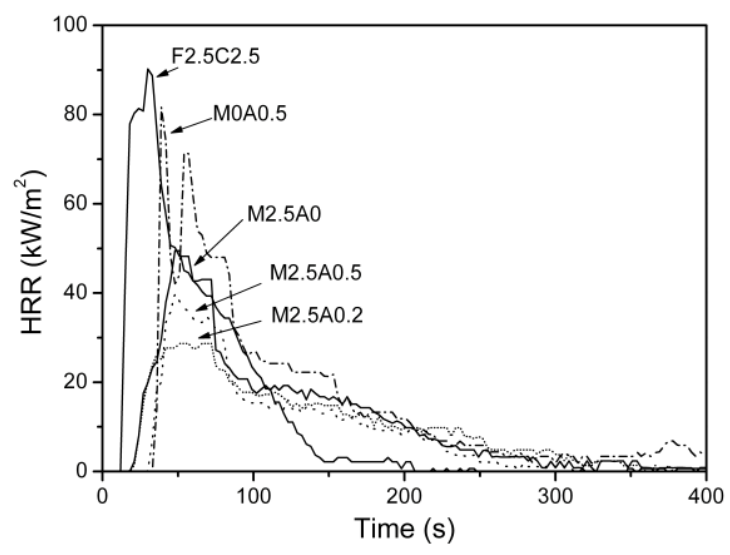

Figure 4. Heat release rate of flame retardancy modified aerogels

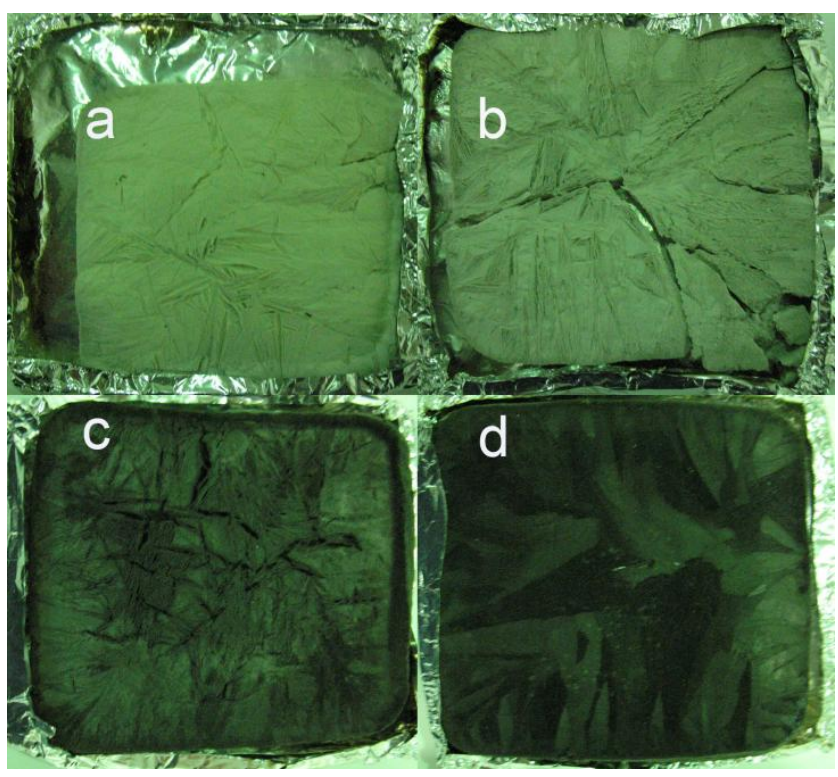

Figure 5. Photos of the chars of flame retardancy modified aerogel samples after cone colorimetry tests: (a)F2.5C2.5, (b)M0A0.5, (c)M2.5A0, (d)M2.5 $\mathrm{A} 0.5$

When 10\% APP was added to F2.5C2.5 (sample M0A0.5), the PHRR decreased by $9.5 \%$ and the FGR also reduced by nearly $30 \%$. Moreover, the time to peak heat released rate (TTPHRR) became 9 seconds longer. This is mainly attributed to the formation of an intumescent char network as discussed in the thermal stability section. On the other hand, APP decomposition 
produced inert gas $\left(\mathrm{NH}_{3}\right)$, which also dilutes the combustive fuel in the gas phase.

It has been widely accepted that clay serves as a flame retardant in polymer aerogels ${ }^{16,17}$. A similar effect was observed in the present work with RCF/CMC aerogels. The PHRR, FGR and time to flame extinguish $\left(\mathrm{t}_{\mathrm{e}}\right)$ decreased significantly with the addition of clay. Furthermore, self-ignition of the samples by the heat radiation was retarded. This is due to the presence of a relatively high quantity of clay in the aerogel (33 wt $\%$ ). According to prior works ${ }^{27,28}$, a high loading of inorganic fillers is necessary to ensure the flame retardant effect on the polymer in foams or foam-like aerogels. The samples modified with clay had layered structures consisting of CMC encapsulated clay platelets as discussed previously. During burning, CMC is decomposes into combustive gas and a porous ceramic clay layer is left.

Gradually, clay layers enrich on the surface of the sample and a cellular inorganic char is created, protecting the material beneath from being burned rapidly and limiting the oxygen content in the flame zone. Moreover, this cellular clay char forms a complex labyrinth through which combustion gases diffuse out of the material ${ }^{16}$. On the other hand, MMT may crosslink with CMC and RCF through hydration reaction, as studied in PVOH-LDH systems ${ }^{18}$.

The best flame retardant performance was observed for the samples containing both clay and APP. M2.5A0.2 displayed approximately $1 / 3$ of PHRR and $1 / 5$ of FGR compared to the unmodified one. This indicates that APP and clay have a synergistic effect.

The photos of the char after burning are given in Figure 5. F2.5C2.5 showed a white residue (Figure 5a). The incorporation of APP turned the color of char into grey (Figure 5b). With the addition of clay, the initial sample shapes were preserved in their black chars (Figure 5c, Figure 5d). This is due to the formation of a dense ceramic skeleton generated by clay assembling when the samples are burned.

In comparison to other bio-based aerogels prepared by the same freeze-drying process, such as wheat gluten ${ }^{26}$ or xanthan gum ${ }^{15}$, the RCF/CMC aerogels showed lower PHRR and much higher residue amount. This is maybe partially due to the presence of some inorganic compounds in the RCF suspension, such as $\mathrm{Al}_{2}\left(\mathrm{SO}_{4}\right)_{3}$ and $\mathrm{CaCO}_{3}$, which are commonly used as additives in the paper industry.

\subsection{FTIR-ATR spectra and analysis.}

FTIR spectroscopy was used to investigate the aerogel char residues which were collected after cone calorimetry tests. The IR patterns are shown in Figure 6.

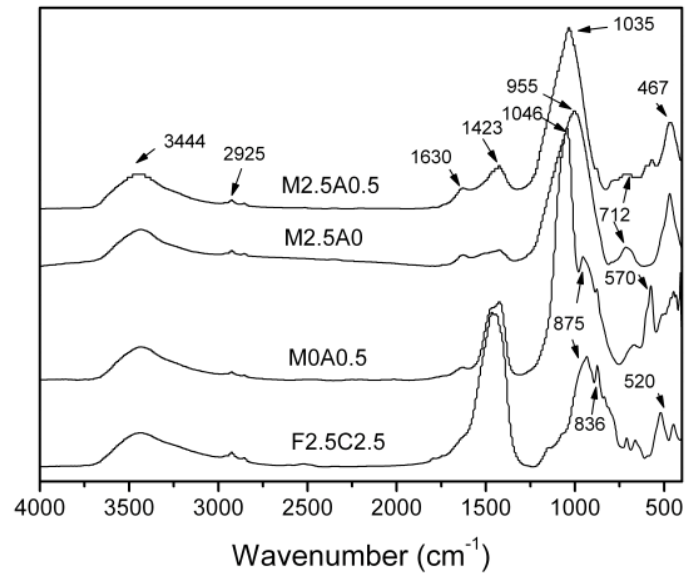

Figure 6. FTIR spectra of aerogel chars.

For the char of sample F2.5C2.5, bands at $3444 \mathrm{~cm}^{-1}$ were related to free $\mathrm{OH}$ stretch. The characteristic peaks at $2925 \mathrm{~cm}^{-1}$ and $1423 \mathrm{~cm}^{-1}$ were associated to $\mathrm{CH}_{2}$ asymmetry stretch and $\mathrm{CH}_{2}$ scissoring vibration, respectively ${ }^{29}$. This indicated that aliphatic compounds existed in the char of cellulose based aerogels. When APP was incorporated, a new band at $1046 \mathrm{~cm}^{-1}$ was observed in the char of M0A0.5, which is attributed to P-O-C stretching 30,31 . During the burning process, APP is firstly decomposed into poly(phosphoric acid) and then it reacts with the hydroxyl group on cellulose through esterification. For the char of M2.5A0, the peaks at $955 \mathrm{~cm}^{-1}$ and $467 \mathrm{~cm}^{-1}$ were associated to $\mathrm{Si}-\mathrm{O}-\mathrm{Si}$ and Al-O group respectively. The new band at $712 \mathrm{~cm}^{-1}$ was related to the $\mathrm{CH}$ stretching in ring compound ${ }^{32}$. The $\mathrm{CH}_{2}$ characteristic band at $1423 \mathrm{~cm}^{-1}$ of sample M2.5A0 decreased significantly in intensity as compared to $\mathrm{F} 2.5 \mathrm{C} 2.5$ char, indicating that the amount of aliphatic groups was significantly reduced. This is possible because clay can catalyze the formation of a stable ring char structure during the polymer pyrolysis in the presence of hydroxyl groups ${ }^{18}$. By adding APP to M2.5A0, the $\mathrm{P}-\mathrm{O}-\mathrm{C}$ band at $1035 \mathrm{~cm}^{-1}$ appeared and overlapped with the $\mathrm{Si}-\mathrm{O}$ band. The poly(phosphoric acid) obtained from APP pyrolysis may have reacted with the hydroxyl groups on the clay surface, releasing water and producing covalent bonds. The resultant char is complex and distinctly different from the chars with APP or clay alone ${ }^{18}$. The band at $1630 \mathrm{~cm}^{-1}$ was due to the $\mathrm{C}=\mathrm{C}$ stretch which only appeared when APP or clay was added, suggesting that samples were not totally oxidized during pyrolysis because of the insulating effect of the formed protective char.

\section{Conclusions}

Recycled cellulose fiber (RCF) from waste paper pulp and a food thickening agent carboxymethylcellulose (CMC), were used to prepare green bio-aerogels by an environmentally friendly freezedrying process. By changing the amount of RCF or CMC, samples showed different microstructures, varying from random to a "house of card" structure. The CMC acted as binding agent for the fibers, effectively improving the mechanical properties of 
aerogels which were also increased with the fiber amount up to $3.75 \mathrm{wt} \%$. The addition of clay did not significantly change the mechanical properties, but greatly enhanced the thermal stability and flame retardant behaviour. Clay platelets played a role of protective thermal barrier and also limited shrinkage of the aerogels during the burning process. Ammonium polyphosphate (APP) and clay played a synergetic effect on the flame retardancy and thermal stability of cellulosic aerogels. This work showed a possible way to produce green foam-like materials as potential candidates for substituting traditional petroleum-based foams.

\section{Acknowledgements}

Authors acknowledge the financial support to this work given by the Spanish Government through the projects MAT 2013-40730$\mathrm{P}$, and the collaboration of Biprocel S.L. in the fiber preparation. Also Liang Wang thanks to the China Scholarship Council for the grant received.

\section{Notes and references}

Centre Catalá del Plàstic, Universitat Politécnica de Catalunya, Colom 114, 08222 Terrassa, Spain.

E-mail:m-sanchez-soto@upc.edu; liangwangupc@gmail.com;

Fax:(+0034) 937841827, Tel: (+0034) 937837022

1 N. T. Cervin, C. Aulin, P. T. Larsson and L. Wågberg, Cellulose, 2012, 19, 401-410.

2 J. T. Korhonen, M. Kettunen, R. H. A. Ras and O. Ikkala, ACS appl. Mater. Inter., 2011, 3, 1813-1816.

3 M. Wang, I. V. Anoshkin, A. G. Nasibulin, J. T. Korhonen, J. Seitsonen, J. Pere, E. I. Kauppinen, R. H. Ras and O. Ikkala, Adv. Mater., 2013, 25, 2428-2432.

4 K. Gao, Z. Shao, X. Wang, Y. Zhang, W. Wang and F. Wang, Rsc Advances, 2013, 3, 15058-15064.

5 H.-B. Chen, B.-S. Chiou, Y.-Z. Wang and D. A. Schiraldi, ACS appl. Mater. Inter., 2013, 5, 1715-1721.

6 T. Pojanavaraphan, R. Magaraphan, B.-S. Chiou and D. A. Schiraldi, Biomacromolecules, 2010, 11, 2640-2646.

7 T. O. Blomfeldt, R. Kuktaite, E. Johansson and M. S. Hedenqvist, Biomacromolecules, 2011, 12, 1707-1715.

8 H. Sehaqui, M. Salajkova, Q. Zhou and L. A. Berglund, Soft Matter, 2010, 6, 1824-1832.

9 D. Klemm, F. Kramer, S. Moritz, T. Lindstrom, M. Ankerfors, D. Gray and A. Dorris, Angew.Chem Int. Ed., 2011, 50, 5438-5466.

10 A. J. Svagan, P. Jensen, S. V. Dvinskikh, I. Furo and L. A. Berglund, J. Mater. Chem., 2010, 20, 6646-6654.

11 M. O. Rahman, M. Hannan, E. Scavino, A. Hussain and H. Basri, Eur. J. Sci. Res., 2009, 25, 96-103.

12 A. J. Svagan, M. A. Samir and L. A. Berglund, Adv. Mater., 2008, 20, 1263-1269.

13 A. J. Svagan, L. A. Berglund and P. Jensen, ACS appl. Mater. Inter., 2011, 3, 1411-1417.

14 A. Liu and L. A. Berglund, Eur. Polym. J., 2013, 49, 940-949.

15 L. Wang, D. A. Schiraldi and M. Sanchez-Soto, Ind. Eng. Chem. Res., 2014, 53 7680-7687.

16 H.-B. Chen, Y.-Z. Wang, M. Sánchez-Soto and D. A. Schiraldi, Polymer, 2012, 53, 5825-5831.

17 L. Wang, M. Sá nchez-Sotoand M. L. Maspoch, Mater. Design, 2013, 52, 609-614.

18 C.-X. Zhao, Y. Liu, D.-Y. Wang, D.-L. Wang and Y.-Z. Wang, Polym. Degrad. and stabil., 2008, 93, 1323-1331.

19 M. C. Monfort, US Patents, 13/697,091, 2011.

20 S. Bandi and D. A. Schiraldi, Macromolecules, 2006, 39, 6537-6545.

21 L. J. Gibson and M. F. Ashby, Cellular solids: structure and properties, 2nd edn., Cambridge university press, 1999.

22 W. Surapolchai and D. A. Schiraldi, Polym. Bull., 2010, 65, 951-960.
23 M. D. Gawryla, O. van den Berg, C. Weder and D. A. Schiraldi, J. Mater. Chem., 2009, 19, 2118-2124.

24 A. E. Donius, A. Liu, L. A. Berglund and U. G. Wegst, J.Mech. Behav. Biomed., 2014, 37, 88-99.

25 D. Liu, Z. Ma, Z. Wang, H. Tian and M. Gu, Langmuir, 2014, 30, 9544-9550.

26 T. O. J. Blomfeldt, F. Nilsson, T. Holgate, J. Xu, E. Johansson and M. S. Hedenqvist, ACS appl. Mater. Inter., 2012, 4, 1629-1635.

27 V. Realinho, L. Haurie, M. Antunes and J. I. Velasco, Composites Part B: Engineering, 2014, 58, 553-558.

28 H.-B. Chen, B. Liu, W. Huang, J.-S. Wang, G. Zeng, W.-H. Wu and D. A. Schiraldi, ACS appl. Mater. Inter., 2014, 6, 16227-16236.

29 G. Socrates and G. Socrates, Infrared and Raman characteristic group frequencies: tables and charts, Third edn., Wiley Chichester, 2001.

30 X. P. Hu, Y. L. Li and Y. Z. Wang, Macromol. Mater. Eng., 2004, 289, 208-212.

31 Y. Li, B. Li, J. Dai, H. Jia and S. Gao, Polym. Degrad. and stabil., 2008, 93, 9-16.

32 R. Setnescu, S. Jipa, T. Setnescu, W. Kappel, S. Kobayashi and Z. Osawa, Carbon, 1999, 37, 1-6. 